\title{
Islamic Fundamentalism and the Doctrine of Jihad
}

\author{
A. J. Abraham
}

USA: Wyndham Hall Press, 2002. 118 pages.

\begin{abstract}
A. J. Abraham, a professor at CUNY and the New York Institute of Technology, as well as a scholar of Near and Middle Eastern History, accurately states that the "Islamic Tendency" has been a significant phenomenon in contemporary times and has "attracted a great deal of negative attention" (p. 2). This compendium packages two prior works: The Warriors of God:
\end{abstract} Jihad (Holy War) and the Fundamentalists of Islam and a monograph entitled Khoumani and Islamic Fundamentalism: Contributions of Islamic Sciences to Modern Civilization. The former is based largely on thesis material coauthored with George I. Haddad at Princeton; the latter is a monograph presented during the 1979 hostage crisis in Iran. The intent of bringing these two works together is ambitious: to foster a "sympathetic" but objective lay understanding of jihad (p. 2) that excludes the sensationalist views exploited by all factions for political aspirations. The author's premise, as noted in the preface, is the need for "balanced yet opposing points of view" (p. 3).

The first work provides a background and insight on jihad that delves beyond the "holy war versus internal struggle" discussion. A methodological breakdown of jihad into seven chapter topics, starting with the hermeneutical "Doctrine of Jihad" and ending with the legalistic "Status of Non-Moslems," follows a logical pedagogy in the conventional understanding of jihad from an ideological framework to an actual interpreted law. Abraham also acknowledges factors leading to the rise of Islamic fundamentalism (p. 12), and thereby provides a succinct framework for further discussion. Inasmuch as these factors could have been more seamlessly tied to current developments across the Middle East, Abraham treats the defunct clash between the Islamic world and the Soviet empire as more a symptom of "resisting secularism" than of addressing the actual appeal of Islamic fundamentalism itself to individuals and the collective Muslim psyche (p. 
25). In a similar manner, it is perplexing and hardly trivial that, while sensitive to the need to keep the presentation current and relevant, the author did not update the use of "Moslem" throughout the work.

One suspects that the academic framework for Abraham and Haddad in the original The Doctrine of Jihad in Islam precluded alternate views of jihad being the principal "instrument to expand Islam throughout the entire world" (p. 67), although alternate reasoning for its appeal and entrenchment in the masses of the so-called Muslim world is encouraged in the concluding remarks that follow the monograph.

The second part of the volume, Abraham's monograph, will be more appealing to general audiences in its flow and subject matter, because its purpose is to foster mutual understanding between Muslims and Christians. The monograph consists of three short chapters that elaborate upon the dialogue and interaction between the Christian and Muslim schools of thought. Starting with a short historical synopsis (aptly titled "Translation and Transition"), it then discusses the theocratic Islamic state and its relationship to other concepts, such as democracy and social liberalism ("The Islamic Ideal and the Modern World") and concludes with an analysis of contemporary issues between the secular, non-Muslim world and the Islamic world ("Tensions and Resolutions for the Future").

The work encapsulated in the monograph exemplifies the "sympathetic" element of the understanding of jihad mentioned in the volume's foreword. The author provides supporting notes and references that are invaluable to the lay reader who wants to understand how Muslims perceive the Christian Trinity (p. 91), and is a useful insight into the concepts communicated in the compendium's first part with regard to the distinctions between the types of "non-Moslems" and their status and role within the Islamic world (p. 60).

The rationale for an Islamic understanding of Christianity is eloquently highlighted by examples in the monograph. This is the author's indelible contribution to the canon of interfaith dialogue. A "sympathetic" insight into the Prophet's adaptation of Islamic law actually shows Islam as a dynamic and inclusive doctrine and conveys Abraham's appreciation of the Islamic state as being more of a proactive approach to social justice then a monolithic response to the influence of non-Arab societies (p. 98). Surprisingly, his concluding remarks framing the compendium do not address these implications, for he does not contrast the basic tenets of Islamic teachings from the Prophet's time with the current psyche of Islamic nations. Furthermore, the author's analysis, even within 
the context of developments in Iran at the time, tends toward broad generalizations: By convenient use of the term fundamentalism to describe the Islamic world, but by not exploring the response of the nonfundamentalist Islamic world beyond the postcolonialist, secular response to modernization, Abraham creates broad ramifications. A more comprehensive analysis of Islamic fundamentalism as a continuum would strengthen his arguments. Also, the premise of a "revolution in reverse" would be effective, had the link between the failures of secularism in the contemporary Islamic world and the conventional interpretation of Islamic doctrines been qualified, rather than epitomized as the fundamentalists' view of a penultimate, encroaching "cultural evolution of modern societies" (p. 114).

In short, Islamic Fundamentalism and the Doctrine of Jihad is an attempt at a fair representation of a doctrine and its influence on the Islamic state. The essence of a balanced view is substantial, but the relationship between the two discrete works, as well as their relevance to the post-9/11 world, could have been discussed more explicitly. Abraham successfully provides insights into the "Moslem" mindset and its origins, for in both works the motivation behind the interpretations is laid out within a historical context, especially with regard to Muslim interactions with the Christian world. Readers will appreciate the dialogue between the Christian and Muslim worlds in the accompanying notes. The compendium ends with a positive perspective that, however controversial a premise, Islamic fundamentalism will evolve due to its interaction with the secular and Christian worlds (p. 114).

Mikhail Ali

Faculty, Mechanical Engineering Technology, Georgian College Barrie, Ontario, Canada 